\title{
Mental Health Adverse Effects of COVID-19 Pandemic on Health Care Workers in North West Ethiopia: A Multicenter Cross-Sectional Study
}

\author{
Sintayehu Asnakew $\mathbb{D}^{\prime}$ \\ Haile Amha ${ }^{2}$ \\ Tilahun Kassew (iD) ${ }^{3}$ \\ 'Department of Psychiatry, School of \\ Medicine, College of Health Science, \\ Debre Tabor University, Debre Tabor, \\ Ethiopia; ${ }^{2}$ Departments of Psychiatry, \\ College of Health Science, Debre Markos \\ University, Debre Markos, Ethiopia; \\ ${ }^{3}$ Department of Psychiatry, College of \\ Medicine and Health Science, University \\ of Gondar, Gondar, Ethiopia
}

Background: The coronavirus has affected nearly every aspect of our lives. Most importantly the health-care workers (HCWs) are under insurmountable psychological pressures which lead them to various mental health problems, such as anxiety, stress, and depression. Objective: This study aimed to assess mental health adverse effects of COVID-19 pandemic on health-care workers in North West Ethiopia 2020.

Materials and Methods: Institutional-based cross-sectional study was conducted. A simple random sampling technique was applied and 419 participants completed the questionnaire. Mental health adverse effects were measured using the depression, anxiety and stress scale (DASS-21). Data were entered into Epi data version 4.4.2 then exported to SPSS version 24 for analysis. Descriptive, bivariate, and multivariate binary logistic regressions with odds ratios and $95 \%$ confidence interval were employed. The level of significance of association was determined at a p-value $<0.05$.

Results: Prevalence of depression, anxiety, and stress in this study was $58.2 \%, 64.7 \%$, and $63.7 \%$, respectively Those who had a medical illness, and mental illness, contact with confirmed COVID-19 pts, and poor social support showed a statistically significant association with depression. Female sex, participants who had families with chronic illness, had contact with confirmed COVID-19 case and poor social support had statistically significant association with anxiety, whereas participants who had families with chronic illness had contact with confirmed COVID-19 cases, and those participants who had poor social support were predictors of stress during COVID-19 pandemic.

Conclusion: The magnitudes of mental health problems were higher and the concerned body should emphasize the continuous assessment of the mental health of health-care workers during this pandemic.

Keywords: depression, anxiety, stress, DASS-21, COVID-19

\section{Background}

The COVID-19 pandemic has challenged the health-care systems worldwide including Ethiopia. It is obvious that during this pandemic, people may be feeling afraid, worried, anxious, and depressed due to the continuous changing alerts regarding the spread of the virus. Since health-care workers are involved in the direct care of patients, they are more likely to be infected than the general population. ${ }^{1}$ This makes them fear of contagion, concern for family health, interpersonal isolation, trust in and support from their organization, and stigma. $^{2-4}$
Correspondence: Sintayehu Asnakew Debre Tabor University, PO Box: 272, Debre Tabor, Ethiopia

Tel +251918162236

Email sintie579@gmail.com 
As a result, health-care workers will be under overwhelming psychological pressure which may lead to various psychological problems, such as anxiety, fear, depression, and stress. ${ }^{5}$

There is increased awareness to protect our frontline workers from COVID-19 exposure and its consequences ${ }^{6}$ and the new norms of the health-care system can affect not only the physical but also the psychological wellbeing of health-care workers during the COVID-19 pandemic. $^{7}$

In a study conducted in China during the corona outbreak, $53.8 \%$ of respondents experienced psychological problems, $16.5 \%$ depressive symptoms, $28.8 \%$ anxiety symptoms, and $8.1 \%$ reported stress. ${ }^{8}$ Similarly, in the study done among nurses in Taiwan who worked during the outbreak of SARS $11 \%$ of them had anxiety, depression, and somatization. ${ }^{9}$ Besides, in a study done on the mental health effect of the severe acute respiratory syndrome (SARS) outbreak on health professionals working in Toronto, $30.4 \%$ of the participants had burnout syndrome, $44.9 \%$ of them had psychological distress, and $13.8 \%$, of health-care workers (HCWs), had posttraumatic stress. $^{10}$

A rapid systematic review conducted on 61 studies revealed that pooled prevalence for anxiety was $45 \%$, to $69 \%$, followed by depression (38\% to $60 \%$ ); and acute stress disorder (31\%, to $82 \%){ }^{11}$

Evidence from systematic review from the previous outbreaks, on the potential impact of COVID-19 on mental health outcomes of health-care providers and the implications for service solutions, revealed that levels of mloderate anxiety ranged from $22.6 \%$ to $44.6 \%$, and severe anxiety from $2.9 \%$ to $5.3 \%$. Moreover, about $50.4 \%$, $34.0 \%$ and $10.5 \%$ of them had symptoms of moderate [or severe] depression, insomnia, and distress, respectively $34 \%$ of health-care workers had mild disturbances, $22 \%$ had moderate disturbances, and $6.2 \%$ had severe disturbances. $^{12}$

Another study done in Singapore revealed that $14.5 \%$ of HCWs screened positive for anxiety, $8.9 \%$ for depression, $6.6 \%$ for stress, and $7.7 \%$ for clinical concern of PTSD. ${ }^{13}$ In addition, a study carried out a year later on the mental health problems of health-care workers following severe acute respiratory syndrome outbreak in Hong Kong the mean depression and anxiety score were $19 \%$, and $14 \%$ respectively. ${ }^{14}$

Likewise, in a study done on mental health and psychosocial problems between medical and nonmedical health workers, in China, medical health workers had a higher prevalence of insomnia $38.4 \%$ vs $30.5 \%$, anxiety $13.0 \%$ vs $8.5 \%$, depression $12.2 \%$ vs $9.5 \%$ as compared with non-medical health workers. ${ }^{7}$ An umbrella review of meta-analyses revealed that the magnitude of depression and anxiety were $24.94 \%$ and $24.83 \%$ respectively. ${ }^{15}$

According to previous studies, mental health problems of health-care workers were affected by the numbers of factors. Among those, sociodemographic characteristics, history of mental and physical illness, having contact with suspected or confirmed COVID-19 patients, poor social support, having family members with chronic illness, lack of training regarding COVID-19 and lack of standardized personal protective equipment.

Many studies have been conducted on the mental health of health-care workers during the pandemic in different countries but there is scarcity of evidences in our country Ethiopia. The results of this study can provide important data to support health-care managers and the allocation mental health services for health-care workers. Moreover, understanding the mental health impacts of COVID-19 on health-care providers is important to identify possible interventions.

Therefore, this study aimed to assess the mental health adverse effects of COVID-19 and associated factors of COVID-19 on health professionals of South Gondar Zone hospitals, Amhara, Ethiopia, 2020.

\section{Materials and Methods Study Settings and Period}

A multi-centered institutional-based cross-sectional study was conducted at South Gondar Zone hospitals, Amhara, from September up to November 2020. South Gondar is about 666 north of the capital city Addis Ababa. There are 8 hospitals in this zone which include Debre Tabor general hospital, Andabet, Estie, Addis Zemen, Ebnat, Lay Gaynt, Tach Gaynt, and Simada primary hospitals. There are about 756 health professionals currently serving these hospitals. Mental health care is one of the services rendered within these hospitals.

\section{Sample Size Determination}

In this study, the sample size was determined by using the single population proportion formula with the assumptions of "P"-50\% (as there were no studies done in Ethiopia in this area), $1.96 \mathrm{Z}$ (standard normal 
distribution), 95\% CI, $\alpha=0.05$, and $10 \%$ non-response rate. Accordingly, a representative sample was calculated to be 423 .

\section{Study Participants and Sampling}

This research was conducted in 8 South Gondar Zone governmental hospitals among health-care works. There are $331,64,59,72,55,69,54$, and 52 health-care workers in Debre Tabor General Hospital, Andabet, Estie, Addis Zemen, Ebnat, Lay Gaynt, Tach Gaynt, and Simada primary hospitals, respectively We proportionally allocated the sample size to each hospital and we invited 423 participants by using simple random sampling technique. Of these, 419 participants completed the questionnaire and two (2) of the eligible participants refused to participate and two (2) questionnaires were incomplete and has been discarded. All health professionals working in these hospitals were included, and those participants who were on annual leave and severely ill were excluded.

\section{Study Variables}

The dependent variables were depression, anxiety, and stress which were measured using the Depression, Anxiety and Stress Scale (DASS-21) as dichotomous variables (yes/no). Independent variables include sociodemographic factors (age, gender, ethnicity, marital status, religion, profession, and having children), clinical variables (family history of medical illness, history of mental illness, having the medical illness, contact with confirmed and suspected COVID-19 cases), psychosocial and material factors consists social support, perceived stigma and lack of adequate and standardized PPE supply.

\section{Data Sources and Measurement}

Data were collected using a standardized self-administered questionnaire by 12 trained health professionals using the Amharic version of the tool. The questionnaire was prepared in English and translated to Amharic and back to English to maintain consistency. Data collectors were trained on how to collect the data and explain the unclear questions and the purpose of the study. Furthermore, they were made aware of ethical principles, such as confidentiality/anonymity/data management, and securing respondents' informed consent for participation.

Mental health adverse effects were measured using the Depression, Anxiety and Stress Scale (DASS-21). The DASS-21 is a 21 -item system that provides independent measures of depression, anxiety, and stress, with recommended severity thresholds. Cutoff scores $>9$, $>7$, and $>14$ indicate a positive screen for depression, anxiety, and stress, respectively. The subscale score for depression was divided into normal (0-9), mild depression (10-12), moderate depression (13-20), severe depression (21-27), and extremely severe depression (28-42). The total anxiety subscale score was divided into normal (0-6), mild anxiety (7-9), moderate anxiety (10-14), severe anxiety (15-19), and extremely severe anxiety $(20-42)$. The stress subscale score was divided into normal (0-10), mild stress (11-18), moderate stress (19-26), severe stress (27-34), and extremely severe stress (35-42). ${ }^{2}$ It had good internal consistency reliability with Cronbach's alpha values in the range of 0.837 to $0.863 .{ }^{16}$ We conducted a reliability analysis for the DASS-21 questionnaire (Amharic version) using the Cronbach's alpha and that it had a high score. The internal consistency was 0.88 for depression, 0.93 for anxiety, 0.95 for stress subscales and 0.96 for the full scale of DASS- 21 .

This tool has been used by many studies in Ethiopian population. ${ }^{17-19}$ A socio-demographic questionnaire was used to assess the patients' background information. Clinical, psychosocial, and material factors were used to assess by yes/no answers of respondents. Social support was measured by the Oslo-3 scale which has a sum score scale ranging from $3-14 .^{4}$ The OSSS-3 contains three items assessing the number of close confidants, perceived level of concern from others and perceived ease of getting help from neighbors. It has good predictive validity ${ }^{20}$ and has been used in a population level study in Ethiopia. ${ }^{21}$

Mental health adverse effects were measured using DASS-21 with cutoff scores $>9,>7$, and $>14$ indicate a positive screen for depression, anxiety, and stress, respectively. ${ }^{2}$

Social support was measured using Oslo 3 items social support scale (OSS-3)

Poor social support was a score of " $3-8$ " on (OSS-3)

Moderate social support was a score of "9-11" (OSS-3)

Strong social support was a score of " $12-14$ " on (OSS-3). ${ }^{4}$

Perceived stigma: To examine the perceived stigma, respondents were asked, "Did you feel stigmatized by the public because of your profession?" and the responses were Yes/No

History of mental illness: To examine a history of mental illness, respondents were asked: "Have you ever been diagnosed with mental illness and treated" and responses were yes/no. 
History of medical illness: To examine a history of medical illness, respondents were asked: "Did you have any medical illness?" and responses were yes/no.

Families with medical illness: To examine families with medical illness, respondents were asked: "Did you have a family member who had a medical illness?" and responses were yes/no.

\section{Data Processing and Analysis}

All collected data were checked for completeness and consistency and entered into Epi-data version 4.4.2 and then exported to SPSS for version 24 for analysis. We computed descriptive, bivariate, and multivariate logistic regression analyses. Factors associated with depression, anxiety, and stress were selected during the bivariate analysis with $\mathrm{p}<0.05$ for further analysis in the multivariable logistic regression analysis. In the multivariable logistic regression analysis, variables with $\mathrm{p}<0.05$ at $95 \% \mathrm{CI}$ with adjusted $\mathrm{OR}$ were considered statistically significant.

\section{Ethical Consideration}

The ethical clearance was obtained from ethical review committee of Debre Tabor University and a permission letter was obtained from each hospital. We received written informed consent from study participants and confidentiality was maintained by omitting personal identifiers.

\section{Patient and Public Involvement}

In the current study, participants were people who are working in South Gondar Zone hospitals, Amhara, Ethiopia. Participants were not involved in the study design and recruitment. The result of this study has been disseminated to the Amhara Regional Health Bureau and each study hospital.

\section{Result}

\section{Sociodemographic Characteristics}

From the total of 423 invited individuals, 419 respondents participated in this study with a response rate of $99.1 \%$. The mean age of the respondents was 32 years and the range was $24-58$ years. About 2/3th of the respondents were males $292(69.7 \%)$. Half of the participants were married 212 (50.6\%), and the majority of participants were orthodox Christian followers 355 (84.7\%), and Amhara by ethnicity 398 (95.0\%). Regarding their profession, most of them were nurses $218(52 \%)$ (Table 1).
Table I Sociodemographic Characteristics of the Participants in South Gondar Governmental Hospitals Amhara Ethiopia 2020 $(n=419)$

\begin{tabular}{|c|c|c|c|}
\hline Characteristics & Category & Frequency & Percent \\
\hline \multirow[t]{5}{*}{ Age } & $<25$ & 42 & 10 \\
\hline & $25-30$ & 223 & 53.2 \\
\hline & $31-40$ & 108 & 25.8 \\
\hline & $4 I-50$ & 26 & 6.2 \\
\hline & $\geq 50$ & 20 & 4.8 \\
\hline \multirow[t]{2}{*}{ Sex } & Female & 127 & 30.3 \\
\hline & Male & 292 & 69.7 \\
\hline \multirow[t]{5}{*}{ Marital status } & Married & 212 & 50.6 \\
\hline & Divorced & 45 & 10.7 \\
\hline & Single & $|4|$ & 33.7 \\
\hline & Separated & 16 & 3.8 \\
\hline & Widowed & 5 & 1.2 \\
\hline \multirow[t]{3}{*}{ Ethnicity } & Amhara & 398 & 95.0 \\
\hline & Tigray & 5 & 1.2 \\
\hline & Oromo & 16 & 3.8 \\
\hline \multirow[t]{5}{*}{ Religious Status } & Orthodox Christian & 355 & 84.7 \\
\hline & Muslim & 33 & 7.9 \\
\hline & Catholic & 10 & 2.4 \\
\hline & Protestant & 11 & 2.6 \\
\hline & Adventist & 10 & 2.4 \\
\hline \multirow[t]{6}{*}{ Profession } & Nurse & 218 & 52 \\
\hline & Doctor & 83 & 19.8 \\
\hline & Laboratory & 62 & 14.8 \\
\hline & Pharmacist & 29 & 6.9 \\
\hline & Midwifery & 15 & 3.6 \\
\hline & Psychiatry & 12 & 2.9 \\
\hline \multirow[t]{2}{*}{ Having children } & Yes & 188 & 44.9 \\
\hline & No & 231 & 55.1 \\
\hline
\end{tabular}

\section{Clinical and Other Factors Related to Mental Health Adverse Effect}

In this study, more than $3 / 4$ th of participants report as they did not get standardized and adequate PPE while caring for COVID-19 patients, and only 50 (11.9\%) of respondents took training regarding COVID-19. About $96(22.9 \%)$ of participants had perceived stigma related to their profession (Table 2).

\section{Mental Health Adverse Effects of COVID-19}

The magnitude of depression, anxiety, and stress in this study on health-care workers related to the COVID-19 
Table 2 Clinical and Other Factors of Mental Health Adverse Effects of Participants Working in South Gondar Governmental Hospitals Ethiopia $2020(n=419)$

\begin{tabular}{|l|c|c|c|}
\hline Characteristics & Category & Frequency & Percent \\
\hline Personal protective & Yes & 94 & 22.4 \\
equipment & No & 325 & 77.6 \\
\hline Having medical illness & Yes & 56 & 13.4 \\
& No & 363 & 86.6 \\
\hline Families with chronic illness & Yes & 143 & 34.1 \\
& No & 276 & 65.9 \\
\hline Hx of mental illness & Yes & 44 & 10.5 \\
& No & 375 & 89.5 \\
\hline Contact with suspected & Yes & 157 & 37.5 \\
COVID-19 cases & No & 262 & 62.5 \\
\hline Contact with confirmed & Yes & 178 & 42.5 \\
COVID-19 cases & No & 241 & 57.5 \\
\hline Training & Yes & 50 & 11.9 \\
& No & 369 & 88.1 \\
\hline Perceived stigma & Yes & 96 & 22.9 \\
& No & 323 & 77.1 \\
\hline Social support & Poor & 243 & 58 \\
& Soderate & 99 & 23.6 \\
& Strong & 77 & 18.4 \\
\hline
\end{tabular}

pandemic were $58.2 \%$ (CI95:53.5, 63), anxiety $64.7 \%$ (CI95:59.9, 69.2), and stress 63.7\% (CI95:59.2, 68.3) respectively.

\section{Factors Associated with Depression}

To determine the association of independent variables with depression, bivariate, and multivariate binary logistic regression analyses were carried out. On the bivariate analysis having the medical illness, Hx of mental illness, contact with suspected and confirmed COVID-19 pts, perceived stigma, and poor social support were found to be associated with depression at a P-value $<0.05$. These factors were entered into multivariable binary logistic regression for further analysis to control confounding effects. In multivariate analysis having the medical illness, $\mathrm{Hx}$ of mental illness contact with confirmed COVID-19 pts poor social support were significantly associated with depression at a p-value less than 0.05 .

The odds of developing depression among respondents with medical illness were 2.52 as compared with those participants who had no history of medical illness $(\mathrm{AOR}=2.52,95 \mathrm{CI} ; 1.18,5.39)$.
The likelihood of developing depression was higher among health professionals with $\mathrm{Hx}$ of mental illness as compared with those respondents with no history of mental illness (AOR=2.72,95CI;1.05,7.01). Similarly, respondents who had contact with the confirmed COVID-19 case $(\mathrm{AOR}=2.59,95 \mathrm{CI} ; 1.37,4.89)$ and poor social support were more affected for depression $(\mathrm{AOR}=1.87,95 \mathrm{CI}$; $1.08,3.22)$ as compared with their counterparts (Table 3).

\section{Factors Associated with Anxiety}

Regarding the anxiety level of the HCWs, females were more anxious than their counterparts $(\mathrm{AOR}=1.85,95 \mathrm{CI}$; $1.09,3.13)$. Health-care providers who had families with chronic illness had a high level of anxiety as compared with those health professionals who had families with no chronic illness (AOR=3.15, 95CI; 1.83, 5.40). The odds of having anxiety were 2.77 times among respondents who had contact with confirmed COVID-19 cases as compared with those respondents who had not the history of contact with the case $(\mathrm{AOR}=2.77,95 \mathrm{CI} ; 1.39,5.52)$. Likewise, those health-care providers who had poor social support were more likely to develop anxiety as compared with participants who had strong social support (AOR=2.64,95CI;1.49,4.67) (Table 4).

\section{Factors Associated with Stress}

Health professional who had families with chronic illness had contact with confirmed COVID-19 cases, and those participants who had poor social support were more likely stressed as compared with their counterparts (Table 5).

\section{Discussion}

Mental health adverse effects such as depression, anxiety, and stress are the most common psychopathology and important public health matters following experiencing epidemics. To the best of our knowledge, this study is the first related to the mental health adverse effect of the COVID-19 pandemic on the health-care providers in the Amhara region, Ethiopia, particularly the South Gondar Zone. We found that the COVID-19 pandemic hurt the mental health of exposed health professionals. According to the result of this study, $58.2 \%$ (CI95:53.5, 63) of the respondents had depression, $64.7 \%$ (CI95:59.9, 69.2) of them had anxiety and 63.7\% (CI95:59.2, 68.3) had stress related to the COVID-19 pandemic. Those who had a medical illness, a history of mental illness, contact with confirmed COVID-19 pts, and poor social support showed a statistically significant association with depression. Female sex, participants who had families 
Table 3 Factors Associated with Depression on Health-Care Providers in South Gondar Governmental Hospitals Ethiopia 2020 $(n=419)$

\begin{tabular}{|c|c|c|c|c|c|}
\hline \multirow[t]{2}{*}{ Characteristics } & \multirow[t]{2}{*}{ Category } & Depression & & COR (95Cl) & AOR (95Cl) \\
\hline & & Yes & No & & \\
\hline Having medical illness & $\begin{array}{l}\text { Yes } \\
\text { No }\end{array}$ & $\begin{array}{l}46 \\
198\end{array}$ & $\begin{array}{l}10 \\
165\end{array}$ & $\begin{array}{l}3.83(1.88,7.83) \\
1\end{array}$ & $\begin{array}{l}2.52(1.18,5.39) \\
\mathrm{I}\end{array}$ \\
\hline $\mathrm{Hx}$ of mental illness & $\begin{array}{l}\text { Yes } \\
\text { No }\end{array}$ & $\begin{array}{l}38 \\
206\end{array}$ & $\begin{array}{l}6 \\
169\end{array}$ & $\begin{array}{l}5.19(2.15,12.59) \\
1\end{array}$ & $\begin{array}{l}2.72(I .05,7.01) \\
I\end{array}$ \\
\hline Contact with suspected COVID-19 pts & $\begin{array}{l}\text { Yes } \\
\text { No }\end{array}$ & $\begin{array}{l}106 \\
138\end{array}$ & $\begin{array}{l}51 \\
124\end{array}$ & $\begin{array}{l}1.87(1.24,2.82) \\
I\end{array}$ & $\begin{array}{l}\mathrm{I} .03(0.6 \mathrm{I}, \mathrm{I} .75) \\
\mathrm{I}\end{array}$ \\
\hline Contact with confirmed COVID-19 pts & $\begin{array}{l}\text { Yes } \\
\text { No }\end{array}$ & $\begin{array}{l}130 \\
114\end{array}$ & $\begin{array}{l}48 \\
127\end{array}$ & $\begin{array}{l}3.02(1.99,4.58) \\
1\end{array}$ & $\begin{array}{l}2.59(1.37,4.89) \\
1\end{array}$ \\
\hline Perceived stigma & $\begin{array}{l}\text { Yes } \\
\text { No }\end{array}$ & $\begin{array}{l}70 \\
174\end{array}$ & $\begin{array}{l}26 \\
149\end{array}$ & $\begin{array}{l}2.31(1.39,3.80) \\
1\end{array}$ & $\begin{array}{l}0.76(0.37, I .57) \\
\text { I }\end{array}$ \\
\hline Social support & $\begin{array}{l}\text { Poor } \\
\text { Moderate } \\
\text { Strong }\end{array}$ & $\begin{array}{l}163 \\
46 \\
35\end{array}$ & $\begin{array}{l}80 \\
51 \\
44\end{array}$ & $\begin{array}{l}2.56(1.53,4.3) \\
I .13(0.62,2.06) \\
I\end{array}$ & $\begin{array}{l}\mathrm{I} .87(1.08,3.22) \\
0.92(0.49,1.73)\end{array}$ \\
\hline
\end{tabular}

with chronic illness, had contact with confirmed COVID-19 with chronic illness, had contact with confirmed COVID-19 case and poor social support had statistically significant assocases, and those participants who had poor social support ciation with anxiety whereas participants who had families were predictors of stress during COVID-19 pandemic.

Table 4 Factors Associated with Anxiety on Health Professionals in South Gondar Governmental Hospitals Ethiopia 2020 ( $\mathrm{n}=419$ )

\begin{tabular}{|c|c|c|c|c|c|}
\hline \multirow[t]{2}{*}{ Characteristics } & \multirow[t]{2}{*}{ Category } & \multicolumn{2}{|c|}{ Anxiety } & \multirow[t]{2}{*}{ COR (95Cl) } & \multirow[t]{2}{*}{ AOR (95Cl) } \\
\hline & & Yes & No & & \\
\hline \multirow[t]{2}{*}{ Sex } & Female & 95 & 32 & $1.96(1.23,3.11)$ & $1.85(1.09,3.13)$ \\
\hline & Male & 176 & 116 & 1 & I \\
\hline \multirow[t]{2}{*}{ Having medical illness } & Yes & 51 & 5 & $6.63(2.58,17.01)$ & $2.4 I(0.85,6.80)$ \\
\hline & No & 220 & 143 & 1 & I \\
\hline \multirow[t]{2}{*}{ Families with chronic illness } & Yes & 114 & 29 & $2.98(1.86,4.78)$ & $3.15(1.83,5.40)$ \\
\hline & No & 157 & 119 & 1 & 1 \\
\hline \multirow[t]{2}{*}{ Hx of mental illness } & Yes & 38 & 6 & $3.86(1.59,9.36)$ & $\mathrm{I} .46(0.53,4.03)$ \\
\hline & No & 233 & 142 & 1 & I \\
\hline \multirow[t]{2}{*}{ Contact with suspected COVID-19 pts } & Yes & 113 & 44 & $1.69(1.10,2.59)$ & $1.03(0.58,1.83)$ \\
\hline & No & 158 & 104 & I & I \\
\hline \multirow[t]{2}{*}{ Contact with confirmed COVID-19 pts } & Yes & $|4|$ & 37 & $3.25(2.09,5.06$ & $2.77(1.39,5.52)$ \\
\hline & No & 130 & 111 & I & I \\
\hline \multirow[t]{2}{*}{ perceived stigma } & Yes & 79 & 17 & $3.17(1.79,5.60)$ & $\mathrm{I} .13(0.5 \mathrm{I}, 2.54)$ \\
\hline & No & 192 & $|3|$ & & I \\
\hline \multirow[t]{3}{*}{ Social support } & Poor & 185 & 58 & $3.8 \mathrm{I}(2.24,6.49)$ & $2.64(1.49,4.67)$ \\
\hline & Moderate & 50 & 47 & $1.27(0.70,2.31)$ & $0.92(0.48,1.75)$ \\
\hline & Strong & 36 & 43 & 1 & 1 \\
\hline
\end{tabular}


Table 5 Factors Associated with Stress on Health-Care Providers in South Gondar Governmental Hospitals Ethiopia 2020 (n=4I9)

\begin{tabular}{|c|c|c|c|c|c|}
\hline \multirow[t]{2}{*}{ Characteristics } & \multirow[t]{2}{*}{ Category } & \multicolumn{2}{|c|}{ Stress } & \multirow[t]{2}{*}{ COR (95CI) } & \multirow[t]{2}{*}{ AOR $(95 \mathrm{Cl})$} \\
\hline & & Yes & No & & \\
\hline \multirow[t]{2}{*}{ Sex } & Female & 90 & 37 & $\mathrm{I} .58(1.0 \mathrm{I}, 2.48)$ & $1.63(0.97,2.75)$ \\
\hline & Male & 177 & 115 & I & I \\
\hline \multirow[t]{2}{*}{ Medical problems } & Yes & 40 & 221 & $2.96(1.45,6.05)$ & $0.91(0.38,2.16)$ \\
\hline & No & 10 & 142 & I & I \\
\hline \multirow[t]{2}{*}{ Families with chronic illness } & Yes & 109 & 34 & $2.39(1.52,3.77)$ & $2.79(1.63,4.76)$ \\
\hline & No & 158 & 118 & I & I \\
\hline \multirow[t]{2}{*}{ Hx of mental illness } & Yes & 38 & 6 & $4.04(1.67,9.79)$ & $1.60(0.58,4.43)$ \\
\hline & No & 229 & 146 & I & I \\
\hline \multirow[t]{2}{*}{ Contact with suspected COVID-19 case } & Yes & 112 & 45 & $1.72(1.12,2.63)$ & $1.06(0.59,1.89)$ \\
\hline & No & 155 & 107 & I & I \\
\hline \multirow[t]{2}{*}{ Contact with confirmed COVID-19 case } & Yes & 145 & 33 & $4.29(2.72,6.75)$ & $3.09(1.53,6.17)$ \\
\hline & No & 122 & 119 & I & I \\
\hline \multirow[t]{2}{*}{ Perceived stigma } & Yes & 84 & 12 & $5.36(2.81,10.19)$ & $2.0 \mathrm{I}(0.86,4.73)$ \\
\hline & No & 183 & 140 & 1 & I \\
\hline \multirow[t]{3}{*}{ Social support } & Poor & 185 & 58 & $3.62(2.13,6.16)$ & $2.49(1.40,4.43)$ \\
\hline & Moderate & 45 & 52 & $0.98(0.54,1.78)$ & $0.66(0.34,1.27)$ \\
\hline & Strong & 37 & 42 & 1 & I \\
\hline
\end{tabular}

In our study, the magnitude of depression was consistent with the study conducted in Libya $56.3 \% .^{5}$ On the other hand, the prevalence of depression on health-care workers was higher than the studies conducted in China $44.37 \%,{ }^{6}$ $12.2 \%,{ }^{7} 50.4 \%,{ }^{8} 15.4 \%,{ }^{9} 40 \%,{ }^{22}$ Spanish $46 \%,{ }^{23}$ systematic review studies $22.8 \%,{ }^{12} 21.7 \%,{ }^{24}$ India $11.4 \%,{ }^{25}$ Singapore $8.9 \%,{ }^{13}$ Nepal $8 \%,{ }^{26}$ Alberta Canada $44.0 \%,{ }^{27}$ Malaysia $21.8 \%,{ }^{28}$ whereas the prevalence of depression in this study was lower than studies done in Turkey $77.6 \%$, $64.7 \%{ }^{30}$ The reason for this discrepancy might be, the simple size difference, the time of research done.

Similarly, the prevalence of anxiety was in line with the study carried out in Turkey $60.2 \% .{ }^{29}$ Conversely, the prevalence of anxiety was higher than the studies conducted in China $46.04 \%,{ }^{6} 44.6 \%,{ }^{8} 13 \%,{ }^{7} 32.6 \%,{ }^{9} 38 \%,{ }^{22}$ Spanish $58.6 \%,{ }^{23}$ systematic review studies $23.2 \%,{ }^{12} 22.1 \%,{ }^{24}$ India $17.7 \%,{ }^{25}$ Singapore $14.5 \%,{ }^{13}$ Nepal $38 \%,{ }^{26}$ Libya $46.7 \%,{ }^{5}$ Alberta Canada $47.0 \%,{ }^{27}$ Turkey $51.6 \%,{ }^{30}$ and Malaysia $31.6 \%{ }^{28}$ The difference could be the sample size difference, the time of the research done, the level of health service development, and the difference in experiences to similar pandemics.

The prevalence of stress in this study was in line with the studies conducted in China $56.59 \%{ }^{6}$ On the other hand, our estimation was higher than the studies conducted in Spanish $41.1 \%,{ }^{23}$ India $3.7 \%,{ }^{25}$ Singapore $6.6 \%,{ }^{13}$ Turkey $41.2 \%{ }^{30}$ and Malaysia $29.1 \%,{ }^{28}$ while the magnitude of stress was lower than studies conducted in China $71.5 \%,{ }^{8} 18.0 \%,{ }^{9}$ Turkey $76.4 \%,{ }^{29}$ and Alberta Canada $85.6 \% .{ }^{27}$ This could be the sample size difference, the health system service difference.

Pertaining to factors associated with depression, those respondents who had medical illness had higher odds of depression as compared with those participants who had no medical illness which was supported by the previous studies. ${ }^{7,31}$ Respondents who had a history of mental illness were more likely affected by depression as compared with their counterparts. This was supported by the study of Nepal. ${ }^{32}$ Professionals who had contact with confirmed COVID-19 pts were more affected for depression, anxiety, and stress as compared with their counterparts. This was supported by the previous studies conducted in China $^{7-9}$ and a rapid review on the impact of COCID-19 on the HCWs. ${ }^{33}$ Moreover, our findings were consistent with the previous studies where it was found that directly contacting the suspected or confirmed COVID patients were the major risk factors that caused psychological distress and anxiety among the HCWs. ${ }^{34,35}$ Additionally, 
poor social support was significantly associated with depression, anxiety, and stress which was consistent with the review study. ${ }^{36}$ Evidence from previous studies has already found the positive effect of social support on the mental health of the HCWs. Furthermore, it is well known that adequate social support provided by partners or spouses, friends represents a protective factor for the psychological well-being. ${ }^{37,38}$ Lack of help to compensate for physical incapacity, emotional support, and someone to talk with about the pandemic or to turn to for advice could increase the risk of mental health problems. ${ }^{39}$

Likewise, women had the increased odds of developing anxiety disorders during the pandemic as compared with men. This finding was supported by the study of China, ${ }^{7}$ Spanish, ${ }^{23}$ and India. ${ }^{25}$

\section{Conclusion}

This study indicated that health professionals are affected by the high level of anxiety, stress, and depression during the COVID- 19 pandemic. The COVID-19 pandemic has disrupted mental health of the population particularly the healthcare workers and the demand for mental health service is increasing. This study highlights the need for high quality, theory- and evidence-based interventions for the well-being of health-care workers during this COVID-19 pandemic. This study also depicted the need for support systems and coping strategies that may assist to reduce stress, anxiety, and depression among health-care workers. These strategies may be developed to target HCWs who are female, who had a medical illness, history of mental illness, those who had contact with confirmed COVID-19 patients, who lacked social support, and those who had families with chronic illness, during their routine practice. Moreover, taking care of the HCWs is crucial to strengthen their mental health, which contributes to the quality of medical services as a frontline fighter during this pandemic.

\section{Data Sharing Statement}

No additional data is available for this study; all data are included in the manuscript.

\section{Ethics Approval and Informed Consent}

This study was conducted in accordance with the Declaration of Helsinki. Ethical approval was obtained from Ethical
Review committee of Debre Tabor University. A formal letter of permission was obtained from each hospital and written informed consent from each participant was taken.

\section{Acknowledgments}

The authors acknowledge Debre Tabor University for reviewing and approval of ethical issues. We extend our gratitude to data collectors, supervisors, and study participants for their time and effort.

\section{Author Contributions}

All authors contributed to data analysis, drafting or revising the article, have agreed on the journal to which the article was submitted, gave final approval of the version to be published, and agree to be accountable for all aspects of the work.

\section{Funding}

This research has no specific grant from any funding agency in the public, commercial, or not-for-profit sectors.

\section{Disclosure}

The authors report no conflicts of interest in this work.

\section{References}

1. World Health Organization. Health Worker Ebola Infections in Guinea, Liberia and Sierra Leone: A Preliminary Report 21 May 2015. World Health Organization; 2015.

2. Le TA, Le MQT, Dang AD, et al. Multi-level predictors of psychological problems among methadone maintenance treatment patients in difference types of settings in Vietnam. Subst Abuse Treat Prev Policy. 2019;14(1):1-10. doi:10.1186/s13011-019-0223-4

3. Abiola T, Udofia O, Zakari M. Psychometric properties of the 3-item Oslo social support scale among clinical students of Bayero University Kano, Nigeria. Malaysian J Psychiatr. 2013;22(2):32-41.

4. Dalgard S. The Oslo 3-items social support scale. 2003.

5. Elhadi M, Msherghi A, Elgzairi M, et al. Psychological status of healthcare workers during the civil war and COVID-19 pandemic: a cross-sectional study. $J$ Psychosom Res. 2020;137:110221. doi:10.1016/j.jpsychores.2020.110221

6. Que J, Le Shi JD, Liu J, et al. Psychological impact of the COVID-19 pandemic on healthcare workers: a cross-sectional study in China. Gen Psychiatr. 2020;33(3):e100259. doi:10.1136/gpsych-2020-100259

7. Zhang W-R, Wang K, Yin L, et al. Mental health and psychosocial problems of medical health workers during the COVID-19 epidemic in China. Psychother Psychosom. 2020;89(4):242-250. doi:10.1159/000507639

8. Lai J, Ma S, Wang Y, et al. Factors associated with mental health outcomes among health care workers exposed to coronavirus disease 2019. JAMA Netw Open. 2020;3(3):e203976-e. doi:10.1001/ jamanetworkopen.2020.3976

9. Zheng R, Zhou Y, Qiu M, et al. Prevalence and associated factors of depression, anxiety, and stress among Hubei pediatric nurses during COVID-19 pandemic. Compr Psychiatry. 2021;104:152217. doi:10.1016/j.comppsych.2020.152217 
10. Lancee WJ, Maunder RG, Goldbloom DS. Prevalence of psychiatric disorders among Toronto hospital workers one to two years after the SARS outbreak. Psychiatr Services. 2008;59(1):91-95. doi:10.1176/ ps.2008.59.1.91

11. Ricci Cabello I, Meneses-Echavez JF, Serrano-Ripoll MJ, et al. Impact of viral epidemic outbreaks on mental health of healthcare workers: a rapid systematic review and meta-analysis. Available at SSRN 3569883. 2020.

12. Pappa S, Ntella V, Giannakas T, Giannakoulis VG, Papoutsi E, Katsaounou P. Prevalence of depression, anxiety, and insomnia among healthcare workers during the COVID-19 pandemic: a systematic review and meta-analysis. Brain Behav Immun. 2020;88:901-907. doi:10.1016/j.bbi.2020.05.026

13. Tan BY, Chew NW, Lee GK, et al. Psychological impact of the COVID-19 pandemic on health care workers in Singapore. Ann Intern Med. 2020;173(4):317-320. doi:10.7326/M20-1083

14. Tam CW, Pang EP, Lam LC, Chiu HF. Severe acute respiratory syndrome (SARS) in Hong Kong in 2003: stress and psychological impact among frontline healthcare workers. Psychol Med. 2004;34 (7):1197. doi:10.1017/S0033291704002247

15. Sahebi A, Nejati B, Moayedi S, Yousefi K, Torres M, Golitaleb M. The prevalence of anxiety and depression among healthcare workers during the COVID-19 pandemic: an umbrella review of meta-analyses. Prog Neuropsychopharmacol Biol Psychiatry. 2021;107:110247. doi:10.1016/j.pnpbp.2021.110247

16. Nordin RB, Kaur A, Soni T, Por LK, Miranda S. Construct validity and internal consistency reliability of the Malay version of the 21-item depression anxiety stress scale (Malay-DASS-21) among male outpatient clinic attendees in Johor. J Med J Malaysia. 2017;72(5):265.

17. Yeshaw Y, Mossie A. Depression, anxiety, stress, and their associated factors among Jimma University staff, Jimma, Southwest Ethiopia, 2016: a cross-sectional study. Neuropsychiatr Dis Treat. 2017;13:2803. doi:10.2147/NDT.S150444

18. Akalu TY, Gelaye KA, Bishaw MA, et al. Depression, anxiety, and stress symptoms and its associated factors among residents of Gondar Town during the early stage of COVID-19 pandemic. Risk Manag Healthc Policy. 2021;14:1073. doi:10.2147/RMHP.S296796

19. Sahile AT, Ababu M, Alemayehu S, et al. Prevalence and severity of depression, anxiety, and stress during pandemic of COVID-19 among college students in Addis Ababa, Ethiopia, 2020: a cross sectional survey. Int J Clin Exp Med Sci. 2020;6(6):126.

20. Bøen H, Dalgard OS, Bjertness E. The importance of social support in the associations between psychological distress and somatic health problems and socio-economic factors among older adults living at home: a cross sectional study. BMC Geriatr. 2012;12(1):1-12. doi:10.1186/1471-2318-12-27

21. Fekadu A, Medhin G, Selamu M, et al. Population level mental distress in rural Ethiopia. BMC Psychiatr. 2014;14(1):1-13. doi:10.1186/1471-244X-14-194

22. Deng Y, Chen Y, Zhang B. Different prevalence trend of depression and anxiety among healthcare workers and general public before and after the peak of COVID-19 occurred in China: a meta-analysis. Asian J Psychiatr. 2021;56:102547. doi:10.1016/j.ajp.2021.102547

23. Luceño-Moreno L, Talavera-Velasco B, García-Albuerne Y, Martín-García J. Symptoms of posttraumatic stress, anxiety, depression, levels of resilience and burnout in Spanish health personnel during the COVID-19 pandemic. Int J Environ Res Public Health. 2020;17(15):5514. doi:10.3390/ijerph17155514

24. Li Y, Scherer N, Felix L, Kuper H, Pietschnig J. Prevalence of depression, anxiety and post-traumatic stress disorder in health care workers during the COVID-19 pandemic: a systematic review and meta-analysis. PLoS One. 2021;16(3):e0246454. doi:10.1371/journal. pone. 0246454
25. Wilson W, Raj JP, Rao S, et al. Prevalence and predictors of stress, anxiety, and depression among healthcare workers managing COVID-19 pandemic in India: a nationwide observational study. Indian J Psychol Med. 2020;42 (4):353-358. doi:10.1177/0253717620933992

26. Gupta AK, Mehra A, Niraula A, et al. Prevalence of anxiety and depression among the healthcare workers in Nepal during the COVID-19 pandemic. Asian J Psychiatr. 2020;54:102260. doi:10.1016/j.ajp.2020.102260

27. Mrklas K, Shalaby R, Hrabok M, et al. Prevalence of perceived stress, anxiety, depression, and obsessive-compulsive symptoms in health care workers and other workers in Alberta during the COVID-19 pandemic: cross-sectional survey. JMIR Ment Health. 2020;7(9):e22408. doi:10.2196/22408

28. Woon LSC, Sidi H, Nik Jaafar NR, Leong Bin Abdullah MFI. Mental health status of university healthcare workers during the COVID-19 pandemic: a post-movement lockdown assessment. Int J Environ Res Public Health. 2020;17(24):9155. doi:10.3390/ijerph17249155

29. Şahin MK, Aker S, Şahin G, Karabekiroğlu A. Prevalence of depression, anxiety, distress and insomnia and related factors in healthcare workers during COVID-19 pandemic in Turkey. $J$ Community Health. 2020;45(6):1168-1177. doi:10.1007/s10900-020-00921-w

30. Elbay RY, Kurtulmuş A, Arpacioğlu S, Karadere E. Depression, anxiety, stress levels of physicians and associated factors in Covid-19 pandemics. Psychiatry Res. 2020;290:113130. doi:10.1016/j.psychres.2020.113130

31. Nobles J, Martin F, Dawson S, Moran P, Savovic J The potential impact of COVID-19 on mental health outcomes and the implications for service solutions. National Institute for Health Research: University of Bristol; 2020. Available from: https://arc-w.nihr.ac.uk/ research-and-implementation/covid-19-response/reports/potentialimpact-of-covid-19-on-mental-health-outcomes-and-the-implications -for-service-solutions. Accessed April 28, 2021.

32. Khanal P, Devkota N, Dahal M, Paudel K, Joshi D. Mental health impacts among health workers during COVID-19 in a low resource setting: a cross-sectional survey from Nepal. Global Health. 2020;16 (1):1-12. doi:10.1186/s12992-020-00621-z

33. De Kock JH, Latham HA, Leslie SJ, et al. A rapid review of the impact of COVID-19 on the mental health of healthcare workers: implications for supporting psychological well-being. BMC Public Health. 2021;21(1):1-18. doi:10.1186/s12889-020-10070-3

34. Xiao X, Zhu X, Fu S, Hu Y, Li X, Xiao J. Psychological impact of healthcare workers in China during COVID-19 pneumonia epidemic: a multi-center cross-sectional survey investigation. J Affect Disord. 2020;274:405-410. doi:10.1016/j.jad.2020.05.081

35. Liu C-Y, Yang Y-Z, Zhang X-M, et al. The prevalence and influencing factors in anxiety in medical workers fighting COVID-19 in China: a cross-sectional survey. Epidemiol Infect. 2020;148.

36. Spoorthy MS, Pratapa SK, Mahant S. Mental health problems faced by healthcare workers due to the COVID-19 pandemic-A review. Asian J Psychiatr. 2020;51:102119. doi:10.1016/j.ajp.2020.102119

37. Hou T, Zhang T, Cai W, et al. Social support and mental health among health care workers during Coronavirus Disease 2019 outbreak: a moderated mediation model. PLoS One. 2020;15(5): e0233831. doi:10.1371/journal.pone.0233831

38. Jenkins R, Elliott P. Stressors, burnout and social support: nurses in acute mental health settings. J Adv Nurs. 2004;48(6):622-631. doi:10.1111/j.1365-2648.2004.03240.x

39. Guay S, Billette V, Marchand A. Exploring the links between posttraumatic stress disorder and social support: processes and potential research avenues. $J$ Trauma Stress. 2006;19(3):327-338. doi: $10.1002 /$ jts. 20124 


\section{Publish your work in this journal}

Neuropsychiatric Disease and Treatment is an international, peerreviewed journal of clinical therapeutics and pharmacology focusing on concise rapid reporting of clinical or pre-clinical studies on a range of neuropsychiatric and neurological disorders. This journal is indexed on PubMed Central, the 'PsycINFO' database and CAS, and is the official journal of The International Neuropsychiatric Association (INA). The manuscript management system is completely online and includes a very quick and fair peer-review system, which is all easy to use. Visit http://www.dovepress.com/testimonials.php to read real quotes from published authors.

Submit your manuscript here: https://www.dovepress.com/neuropsychiatric-disease-and-treatment-journal 